\title{
HangAut Game: Um Jogo da Forca Mobile Adaptado para Crianças com Autismo
}

\author{
Jean B. Teixeira ${ }^{2}$, Paulo N. B. Saturnino ${ }^{2}$, Benedito F. A. Oliveira ${ }^{2}$, Roberto L. L. \\ Junior $^{2}$, Ezequiel B. Farias ${ }^{1}$, Mônica X. C. Cunha ${ }^{2}$ \\ ${ }^{1}$ Instituto da Computação - Universidade Federal de Alagoas (UFAL) - Maceió - AL - \\ Brasil \\ ${ }^{2}$ Coordenadoria de Informática - Instituto Federal de Alagoas (IFAL) - Maceió, AL - \\ Brasil

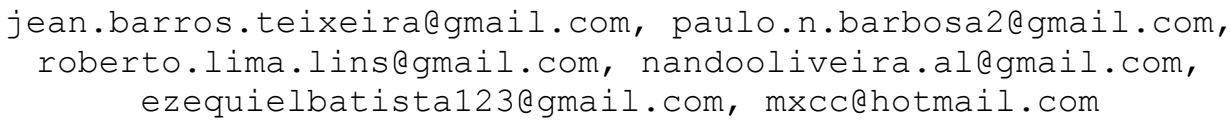

Resumo: Jogos sérios para dispositivos móveis podem auxiliar no processo ensino-aprendizagem de crianças com autismo. Nesse contexto, o presente trabalho se propõe a desenvolver e validar um jogo da forca adaptado para dispositivos móveis que tem como objetivo auxiliar o processo de ensinoaprendizagem de crianças com autismo. O jogo baseia-se em princípios da análise do comportamento e aspectos do programa de ensino estruturado TEACCH. O procedimento metodológico envolveu as etapas de levantamento de requisitos, prototipação, implementação e validação com crianças autistas. Tendo como resultado o jogo HangAut Game, alinhado com o formato do ensino estruturado e favorecendo a aprendizagem sem erro.

\section{Cenário de Uso}

O autismo é um distúrbio do desenvolvimento que se caracteriza por alterações presentes desde idade muito precoce, com impacto múltiplo e variável em áreas nobres do desenvolvimento humano como comunicação, interação social, aprendizado e capacidade de adaptação (SCHWARTZMAN, 2011).

No que diz respeito a comunicação, o indivíduo com autismo possui dificuldade em utilizar todos os aspectos da linguagem verbal ou não-verbal, incluindo gestos, expressões faciais, linguagem corporal, ritmo e modulação na linguagem verbal. Em relação a socialização, evidencia-se a dificuldade de relacionar-se com os outros, mostrando incapacidade de compartilhar sentimentos, gostos e emoções. Por sua vez, a dificuldade com o uso da imaginação se caracteriza por rigidez e inflexibilidade nas várias áreas do pensamento, linguagem e comportamento da criança, percebida por uma forma de brincar desprovida de criatividade e pela exploração peculiar de objetos e brinquedos (MELO, 2007).

Todas estas dificuldades comprometem a aprendizagem de crianças com autismo, tornando o ensino uma tarefa desafiadora. Apesar dos comprometimentos cognitivos que o autismo acarreta, acredita-se que o ensino é possível utilizando recursos e métodos adequados, em programas individualizados, elaborados de acordo com as necessidades específicas do aluno (FERNANDES, 2010). Muitas abordagens têm sido elaboradas com este propósito trabalhando carências específicas no autista. Apesar da limitação existente em muitos modelos resultados animadores tem sido registrados. 
V Congresso Brasileiro de Informática na Educação (CBIE 2016)

Anais dos Workshops do V Congresso Brasileiro de Informática na Educação (CBIE 2016)

\subsection{Análise do Comportamento}

Os principais métodos utilizados no tratamento de crianças com autismo baseiamse na abordagem psicológica conhecida como Análise do Comportamento (AC). A AC defende que o comportamento deve ser estudado considerando a tríplice relação de contingências estímulo-resposta-consequência e identifica uma nova categoria do comportamento humano conhecida como comportamento operante. Nessa vertente, introduz-se o conceito de aprendizagem por consequência mediante a afirmação de que os homens agem sobre o mundo e o modificam e, por sua vez, são modificados pelas consequências de sua ação (SKINNER, 1980).

De acordo com a AC a probabilidade de um indivíduo repetir a mesma resposta futuramente, diante das mesmas condições ambientais (estímulos), irá variar de acordo com as consequências (reforço ou punição) que ele obtiver para essas respostas. A consequência é reforçadora quando aumenta a probabilidade de ocorrência de uma determinada ou almejada resposta e é considerada punição quando esta diminui a probabilidade de ocorrência deste comportamento (MOREIRA; MEDEIROS, 2007).

\subsection{TEACCH}

O programa para Tratamento e Educação de Crianças com Autismo e com Distúrbios Correlatos da Comunicação (TEACCH) foi construído com base na análise do comportamento. O TEACCH tem como objetivo favorecer o processo ensinoaprendizagem de pessoas com autismo, utilizando um ambiente visualmente estruturado e com atividades adaptadas, elaboradas com dicas visuais, como figuras, fotos, imagens, sons e animações. As dicas utilizadas vão sendo reduzidas à medida em que a criança vai adquirindo as habilidades e os conteúdos propostos (FONSECA; CIOLA, 2014).

Esse procedimento de redução de ajudas, suportes e pistas é baseado na técnica de hierarquia de dicas, que consiste no uso e retirada gradual de dicas oferecidas às crianças para garantir que a realização de atividades que estimulam a aprendizagem ocorra sem erros. O esvanescimento foi a técnica escolhida para a apresentação e retirada de dicas em cada um dos níveis do aplicativo HangAut. Esta técnica caracteriza-se pela apresentação de estímulos antecedentes (dicas) para o indivíduo que está aprendendo e a retirada gradual dos mesmos (MELLO; CARMO; HANNAH, 2014). A aplicação desta estratégia de ensino é importantíssima para o processo de desenvolvimento cognitivo dos autistas, pois trabalha em cima de características comuns a este público como a preferência por rotinas, além de excessiva dificuldade em manter o foco atencioso na execução de atividades que não são de seu interesse. Indivíduos com autismo são mais inclinados às rotinas, pois estas, dão ideia de controle aos mesmos. Com o domínio de suas ações a criança fica mais segura para realizar suas atividades, pois já sabe o que se espera dela durante o processo interventivo evitando assim a frustração e as crises de "birra" que dificultam o aprendizado.

Adequar o processo de ensino mediante a inserção destes mecanismos é bastante oneroso para os envolvidos com o processo, pois exige a necessidade de elaboração de variadas atividades contendo os mais diversos elementos e dicas para o ensino de cada habilidade. O processo de construção da atividade envolve tanto a pesquisa pelas preferências de cada criança além da confecção dos elementos e dicas que devem acompanhar o nível cognitivo do individuo e representar a habilidade que se quer trabalhar. Deve-se considerar também o tipo de material utilizado, uma vez que a constante manipulação das atividades e elementos acaba por diminuir o tempo de vida útil deles sendo necessário assim nova confecção. 
Apesar dos obstáculos e dificuldades enfrentados na preparação e aplicação do programa TEACCH sabe-se que o mesmo é efetivo na conduta autista e representa diferencial para o ensino de habilidades a este público. A difusão desse programa pelas associações do nosso país tem sido cada vez maior, porém as instituições existentes em nosso território não absorvem a totalidade de autistas diagnosticados, limitando assim os efeitos benéficos na aplicação do TEACCH e reduzindo assim o seu poder de alcance, uma vez que apenas as associações dão suporte na aplicação do modelo.

Com o intuito de auxiliar para a melhoria desse cenário foi criado o HangAut Game um jogo da forca mobile adaptado para auxiliar no processo de ensinoaprendizagem de crianças com autismo. O jogo é baseado em aspectos do programa TEACCH e nos princípios da análise do comportamento sendo voltado para a prática de habilidades do processo de alfabetização por meio do reforço na construção de palavras.

\subsection{Trabalhos Correlatos}

\section{ABC Autismo}

É um aplicativo móvel desenvolvido com o objetivo de auxiliar no desenvolvimento cognitivo de crianças com autismo por meio de atividades adaptadas (FARIAS; CUNHA, 2013). O ABC Autismo utiliza premissas do programa TEACCH. As atividades propostas no aplicativo estão divididas em 4 níveis. Os três primeiros são voltados a estimulação de pré-habilidades de leitura e escrita. O quarto nível, por sua vez, que tem uma das telas retratadas na figura 1, se propõe a ensinar a escrita de palavras associadas às respectivas imagens, usando o formato peculiar do programa TEACCH. Este nível serviu como base para a construção do jogo HangAut Game.

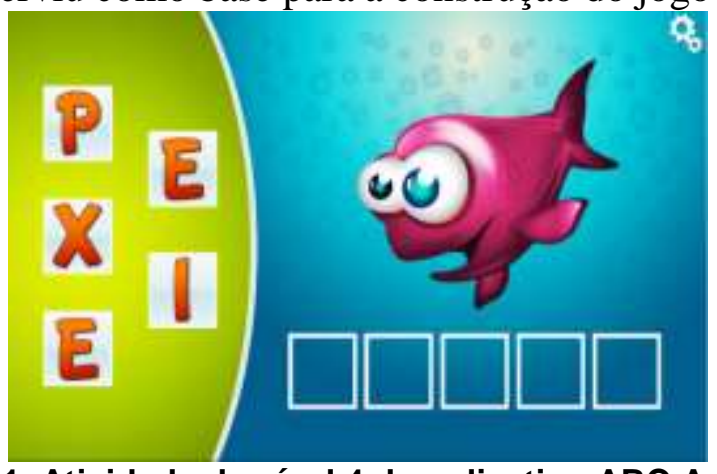

Figura 1. Atividade de nível 4 do aplicativo ABC Autismo.

\section{Aiello}

O Aiello é um jogo que auxilia na alfabetização de pessoas com autismo. Sua proposta é ajudar a criança a associar nomes a imagens de objetos, ampliando seu vocabulário. É um jogo simples que tem como personagem principal um esquilo que interage com a criança solicitando uma determinada palavra para associar com a imagem exibida ou com a própria palavra. A figura 2 representa a tela principal do jogo Aiello. A associação de palavra com imagem é uma proposta interessante, só que carece de dicas para uso com pessoas com autismo. E uma interface mais direcionada, sem distratores. 


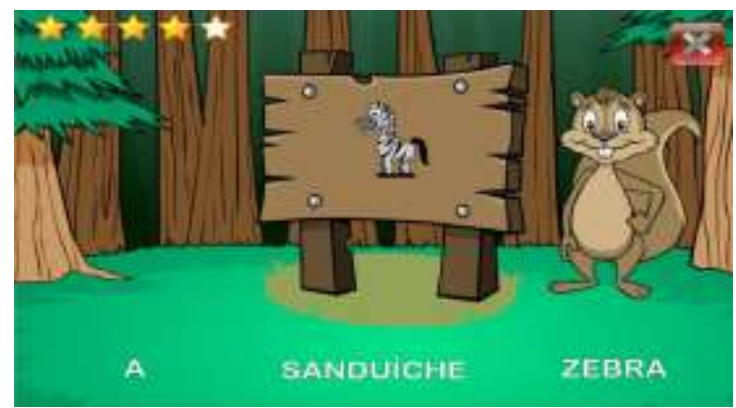

Figura 2. Tela da atividade do aplicativo Aiello.

\section{WorldTour}

WorldTour é fruto de uma pesquisa científica e explora a curiosidade das crianças autistas por diferentes partes do mundo, através de diversas atividades lúdicas, tais como jogos de conexão, quebra-cabeças, montagem de roteiros etc, que são subdivididas em níveis de dificuldade para atender aos diferentes perfis (SOUZA; COSTA; CASTRO, 2012). Percebe-se a ausência de menção à quais metodologias de aprendizagem voltadas para pessoas com autismo o jogo se baseia. Além disso, o artigo não descreve o teste de validação da ferramenta com o próprio público alvo, no caso, crianças com autismo.

Após a pesquisa dos jogos correlatos, foi possível perceber que, com exceção do ABC Autismo, os demais não apresentam aderência a programas de ensino voltados a pessoas com autismo, especialmente na questão de visualização dos elementos, inserção e retirada gradual de dicas, dentre outros requisitos. Tudo isso reforça a proposta do Jogo da forca adaptado às necessidades de crianças com autismo, o HangAut, com atenção aos detalhes que envolvem esse universo, a fim de proporcionar aprendizagem sem erro.

\section{Desenvolvimento}

Inicialmente foi realizado um estudo bibliográfico para obter informações necessárias sobre o universo autista e assim compor um escopo de projeto baseado em um jogo da forca adaptado às necessidades e características de um indivíduo com autismo. Verificamos neste processo características intrínsecas ao contexto autista bem como ações voltadas ao desenvolvimento de habilidades nestes indivíduos. Tendo em vista o estilo tradicional de um jogo da forca, observou-se a necessidade de atividades estruturadas, com hierarquia de dicas, beneficiando uma aprendizagem sem erro para a criança, seguindo recomendações estabelecidas por um dos programas levantados: o TEACCH.

Em busca de aprofundamento sobre o autismo, foram realizadas algumas visitas a uma instituição de caráter assistencial, sem fins lucrativos, que realiza atendimento multidisciplinar a crianças e adolescentes com autismo. Durante as visitas foi possível observar comportamentos específicos desses indivíduos em diferentes situações de aprendizado e diante de diferentes estímulos. Também foram realizadas entrevistas com alguns profissionais da equipe de pedagogia e psicologia da instituição, que revelaram informações cruciais tanto para o design quanto para a lógica do jogo.

As observações in loco da aplicação e da execução das atividades adaptadas do Programa TEACCH, por parte das crianças e adolescentes, somadas às orientações dos profissionais da instituição visitada, serviram de base para o delineamento das ideias necessárias para a implementação do jogo da forca adaptado para crianças com autismo. 
Após a organização de todas as características do jogo, foi iniciada a fase de desenvolvimento, nesta escolhemos um framework multiplataforma, escrito na linguagem LUA, para codificação do aplicativo. Este framework é capaz de compilar o mesmo código para diferentes plataformas, possibilitando assim disponibilizar o aplicativo para as plataformas Android, IOs e Windows Phone. Este framework é conhecimento como Corona SDK. Tendo toda a base definida para o desenvolvimento do programa, foram estabelecidos os períodos de implementação obedecendo à metodologia Scrum.

Finalizadas todas as etapas relacionadas ao planejamento do desenvolvimento foi possível dar início à fase de codificação do aplicativo, com o intuito de gerar uma versão de testes da ferramenta, nomeada como versão beta do HangAut Game. Com essa versão foi possível retornar à instituição colaboradora do projeto e realizar uma validação inicial com algumas crianças e profissionais, visando atestar as características inerentes a aplicação destinadas ao público alvo.

\section{Apresentação do Software : HANGAUT GAME}

O objetivo foi desenvolver um jogo para dispositivos móveis, tais como smartphones e tablets, com o intuito de auxiliar o processo de ensino-aprendizagem de crianças com autismo. O jogo é uma adaptação do tradicional Jogo da Forca, porém com modificações para atender as necessidades especiais deste público peculiar, e toma como base alguns aspectos dos principais programas utilizados no processo de educação de crianças com autismo, tais como o TEACCH e o ABA.

$\mathrm{O}$ jogo se apoia principalmente na utilização de técnicas de aprendizagem sem erro, como hierarquia e esvanecimento de dicas. As dicas presentes no jogo mudam conforme a criança avança entre os diferentes níveis. A cada nível a dica apresentada deixa menos evidente o comportamento esperado. Além das dicas, o jogo também possui diferentes categorias de palavras. A categoria é escolhida pelo jogador ou profissional que esteja acompanhando a criança e uma palavra dentro desta categoria será escolhida de forma aleatória com base no nível selecionado e de acordo com um conjunto de palavras cadastradas no banco de dados do jogo. As atividades do jogo foram divididas em 05 níveis, cada uma apresentando dicas específicas, com a intenção de proporcionar uma aprendizagem sem erro. Todas as telas das atividades possuem uma área de armazenamento com elementos que representam algumas letras do alfabeto, entre elas, as letras que formam a palavra sorteada.

O nível 1 do jogo baseia-se no emparelhamento simples de cores. As letras da palavra sorteada são destacadas com as respectivas cores das lacunas para onde devem ser armazenadas. Neste nível, cada lacuna também possui, em marca d'água, a sinalização da letra a preencher. Além disso, a imagem colorida, correspondente a palavra, também aparece em destaque, na tela, conforme visualizado na figura 6 .

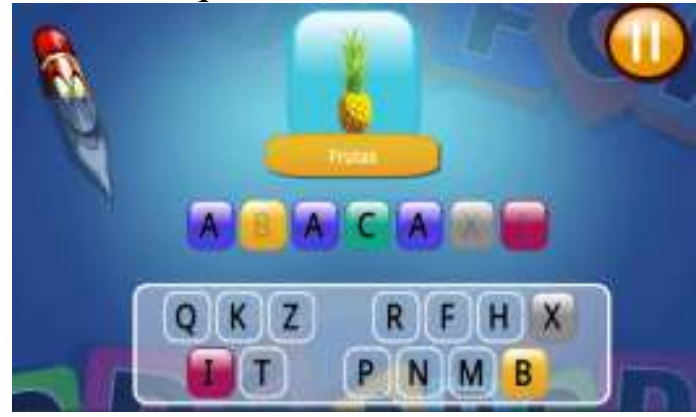

Figura 6. Tela da atividade de nível 1 do Hangaut Game. 
V Congresso Brasileiro de Informática na Educação (CBIE 2016)

Anais dos Workshops do V Congresso Brasileiro de Informática na Educação (CBIE 2016)

No nível 2, o emparelhamento ocorre entre a letra com fundo colorido e a lacuna sinalizada com a borda da mesma cor. Outra redução de dica foi a supressão da marca d'água da letra esperada nos espaços. Também a imagem passou a aparecer na escala de cinza, conforme apresentado na figura 7.

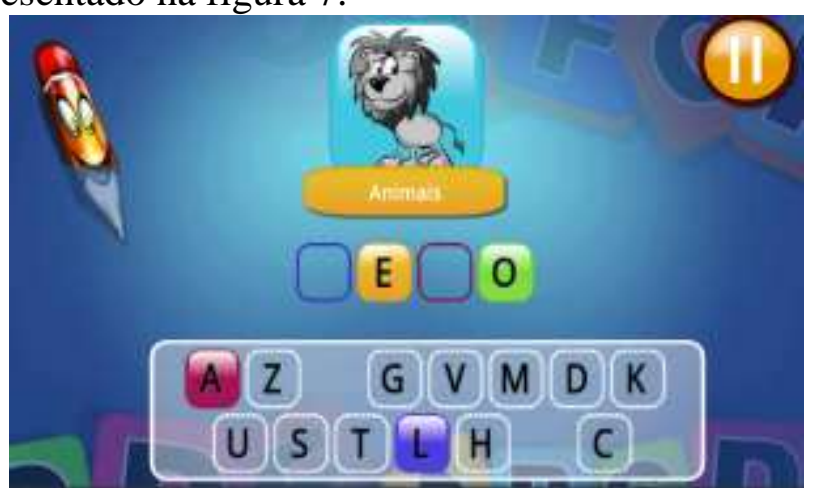

Figura 7. Tela da atividade de nível 2 do Hangaut Game.

No nível 3, as dicas de emparelhamento de cores, entre os elementos e as lacunas para onde devem ser arrastados, foram removidas. A dica, neste nível, consiste em destacar em cinza todas as letras que compõem a palavra. No nível 4 , por sua vez, dois novos elementos foram incluídos na atividade: a exigência da sequência na formação da palavra, para isso foi introduzido um indicador, bem como a dica da sonoridade da letra esperada para a lacuna. As figuras 8 e 9 apresentam, respectivamente, o nível 3 e o nível 4 do jogo Hangaut Game.

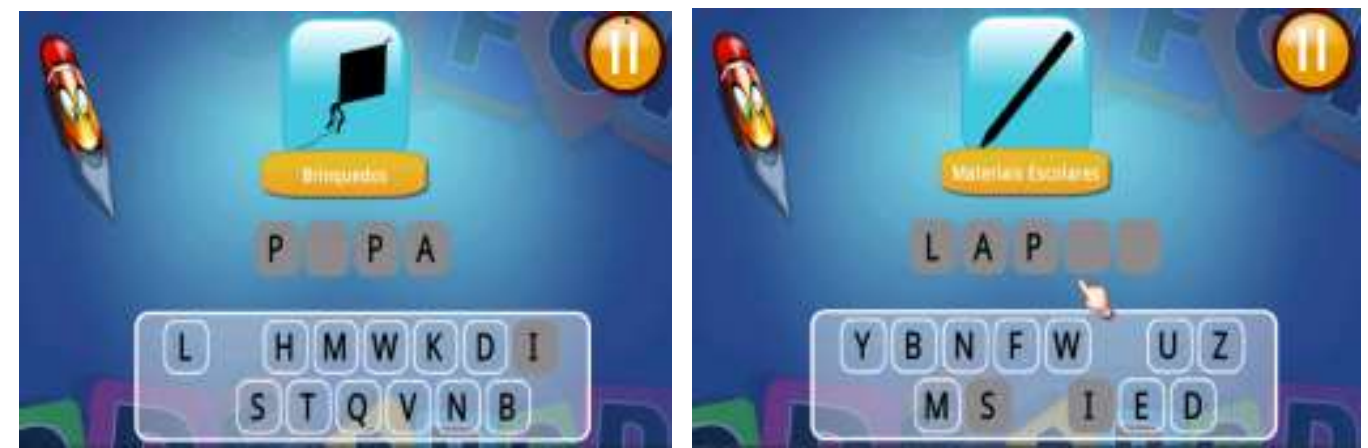

Figuras 8 e 9. Telas de atividade do nível 3 e do nível 4 do Hangaut Game.

O quinto e último nível do jogo, cuja tela está apresentada na figura 10, é voltado para crianças já alfabetizadas. As atividades passam a trabalhar com dicas textuais, relacionadas a palavra, retirando totalmente demais dicas como o emparelhamento de letras e a apresentação prévia de uma imagem.

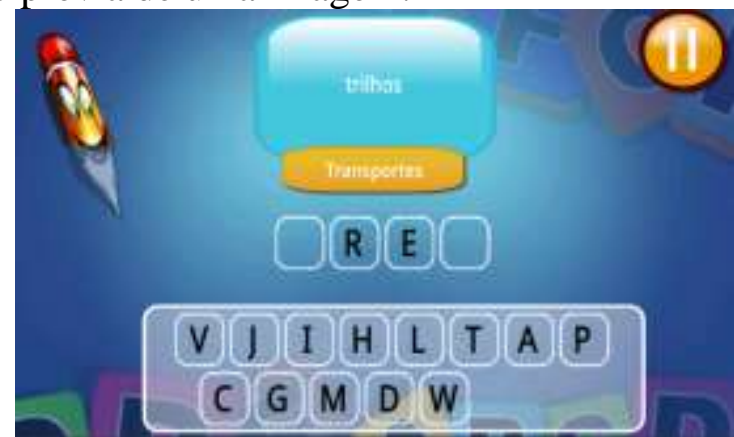

Figura 10. Tela da atividade de nível 5 do Hangaut Game. 
V Congresso Brasileiro de Informática na Educação (CBIE 2016)

Anais dos Workshops do V Congresso Brasileiro de Informática na Educação (CBIE 2016)

\section{CONSIDERAÇÕES FINAIS}

Uma validação inicial do Hangaut Game foi realizada com algumas crianças e profissionais na associação onde foram levantados os requisitos. O objetivo foi averiguar o alinhamento das atividades propostas no jogo, especialmente no que se refere à questão das dicas e esvanecimento das mesmas, com as necessidades do público alvo, bem como a coerência com os programas utilizados no tratamento de pessoas com autismo em especial as metodologias ABA e TEACCH.

Foram elaborados 02 questionários com perguntas fechadas, sendo um direcionado aos profissionais e o outro para ser preenchido pelo pesquisador, com ajuda do terapeuta da criança com autismo, durante a observação da utilização do jogo. Todo o processo de validação realizado na associação foi autorizado pela diretoria e pelos pais das crianças que participaram do teste. Utilizamos a escala Likert considerando os parâmetros Ruim, Razoável, Bom e Muito Bom para avaliar o primeiro questionário e o intervalo de 0 a 10 para avaliar o segundo questionário. Levantamos alguns quesitos para a análise, dentre eles podemos destacar: autonomia, facilidade de manipulação dos elementos dentro da interface, nível de entendimento das dicas apresentadas, nível de concentração durante a execução das atividades, percepção da proposta de cada atividade, satisfação da criança após execução do aplicativo. Nove crianças autistas e nove profissionais de variadas áreas (pedagogia, psicopedagogia e psicologia) participaram do estudo. Ao final, uma questão aberta foi apresentada com o intuito de captar sugestões e críticas ao jogo.

No geral os profissionais entrevistados deram parecer favorável as funcionalidades e características da aplicação. Com relação aos resultados do processo de manipulação do aplicativo por parte das crianças autistas a figura 11 apresenta a média das respostas dos profissionais ao primeiro formulário, a partir da observação da utilização do Hangaut Game pelas crianças selecionadas. É possível observar um bom desempenho e aceitação por parte desses usuários com relação as atividades propostas. O jogo Hangaut Game foi desenvolvido visando trazer para um ambiente mais interativo técnicas utilizadas e consolidadas no processo de ensino-aprendizagem de crianças com autismo, existentes no TEACCH e no ABA. Devido a esse embasamento, espera-se que o jogo se torne uma ferramenta importante e eficaz na alfabetização de crianças com autismo favorecendo o aprendizado com uma interface atrativa e lúdica. Futuramente planeja-se o aumento na quantidade de categorias, juntamente com a quantidade de palavras, com o intuito de auxiliar na ampliação do vocabulário da criança.

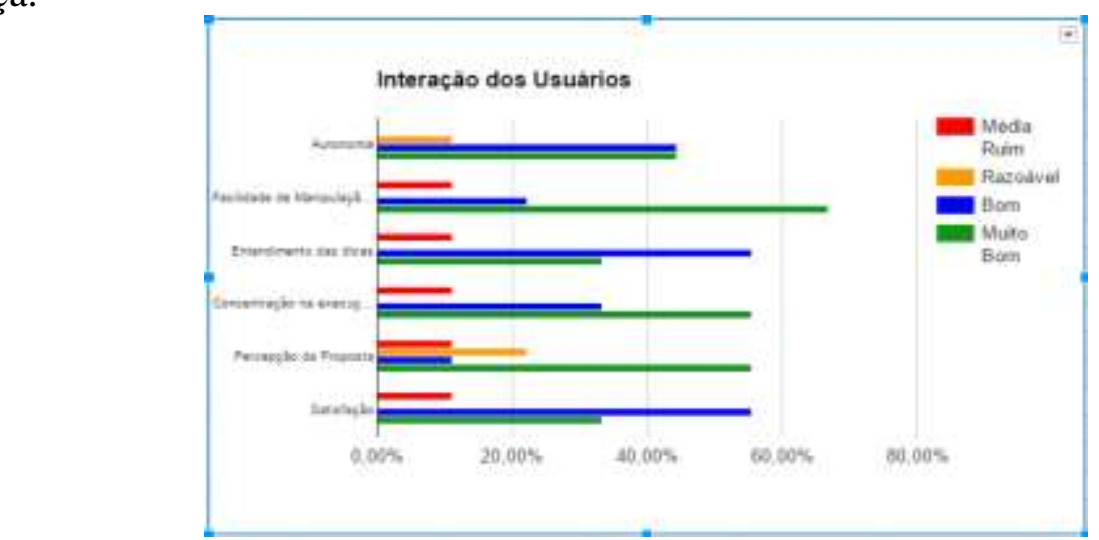

Figura 11. Média das respostas do formulário de observação da execução das atividades. 
Além disso, pretende-se capturar os dados produzidos durante a execução das atividades para oferecer subsídios à equipe multidisciplinar que acompanha a criança para tomada de decisões. Espera-se que esta aplicação possa ser uma alternativa viável para ampliação do escopo interventivo do programa TEACCH e ser amplamente utilizado por crianças autistas que esperam por uma vaga em associações do nosso país.

\section{REFERÊNCIAS}

FARIAS, E. B.; CUNHA, M. X. C. Protótipo de uma Ferramenta de Software para Apoio no Tratamento de Crianças com Autismo. In: Simpósio Brasileiro de Sistemas de Informação, 9, 2013, João Pessoa - PB. Anais... João Pessoa: SBSI, 2013, pp 332-342.

FERNANDES, S. F. N. A adequabilidade do modelo Teacch para a promoção do desenvolvimento da criança com autismo. Porto-Portugal, 2010. $61 \mathrm{f}$. Dissertação (Mestrado em Educação Especial) - Escola Superior de Educação Paula Frassinetti, 2010 .

FONSECA, M. E. G.; CIOLA, J. C. B. Vejo e Aprendo - Fundamentos do Programa TEACCH: O Ensino Estruturado para pessoas com Autismo. São Paulo: Booktoy, 2014.

MELLO, A. M. S. Ros de. Autismo: Guia Prático. 7 ed. Brasília: CORDE, 2007.

MELO, R. M.; CARMO, J. D. S.; HANNA, E. S. Ensino sem erro e aprendizagem de discriminação. Temas em Psicologia, v. 22, n. 1, p. 207-222, 2014.

MOREIRA, M. B.; MEDEIROS, C. A. Princípios básicos de análise do comportamento. Porto Alegre: Artmed, 2007.

PASSERINO, L; SANTAROSA, L. M. C.; TAROUCO, L. M. R. Pessoas com Autismo em Ambientes Digitais de Aprendizagem: estudo dos processos de Interação Social e Mediação. In: Simpósio Brasileiro de Informática na Educação, 17, 2006. Anais.... Brasília: SBIE, 2006

SCHWARTZMAN, J. S. Transtornos do espectro do autismo: conceitos e generalidades. In: Transtornos do Espectro do Autismo. SCHWARTZMAN, J. S.; ARAUJO, C. São Paulo: Memnon, 2011.

SKINNER, B. F. Contingências do reforço: Uma análise teórica. São Paulo: Abril Cultural, 1980.

SOUZA, F. R. M.; COSTA, E. A. B; CASTRO, T. H. C. WorldTour: Software para Suporte no Ensino de Crianças Autistas. In: Simpósio Brasileiro de Informática na Educação, 23, 2012. Anais... Rio de Janeiro: SBIE, 2012. 